\title{
Biases in the Han Dynasty's View Towards Different Countries Along the Silk Road
}

\author{
Joseph Haoyang Yu
}

Dulwich College Shanghai, Shanghai 201206, China, Josephhyyu@hotmail.com

\begin{abstract}
The Han Dynasty, from 206 BCE to 200 CE, could be considered as the origin of the Silk Road. The Silk Road acted as a trading route, connecting countries from the capital of Han, all the way to Rome. During this period, the Han produced many historical books, writing about different countries towards the west. The present article seeks to explore the biases and stereotypes within official Han historical books, to argue that they changed their view and bias towards different countries along the Silk Road, depending on their distance from Han, their power compared to the Han, and whether they were nomadic or sedentary societies.
\end{abstract}

Keywords: Han Dynasty, Silk Road, bias, stereotypes, distance, power, social structure

\section{INTRODUCTION}

There have many historical text on the silk road and many historians have studied these texts and used them to explore certain areas of knowledge. They are able to explore it through the Eurasian perspective. However, there have been no articles analysing the Silk Road from a global perspective. From this broad perspective, the article will not be picking out specific details out of the vast amount of evidence provided in the texts. Rather, the article will be attempting to spot general patterns through a broader scope, more specifically patterns in terms of stereotypes and biases. Biases and stereotypes have been present since the start of human civilisation, as it is a natural thought process humans have. However, the importance of stereotypes and biases and how they affect the way people interact with one another has only come under the spotlight within the $21^{\text {st }}$ century. That is why this article will argue from a more modern perspective and attempt to find a certain degree of correlation between biases and the portrayal of countries along the Silk Road and their distance, power and social structure in relationship to the Han. The article will recognize these biases and stereotypes and give reasons why these biases might have occurred in historical context.

The Han Dynasty, from 206 BCE to 200 CE, could be considered as the origin of the Silk Road. The Silk Road acted as a trading route, connecting countries from the capital of Han, all the way to Rome. There have been many articles that analyse the language and biases of Chinese texts and the meaning of it. However, there have been no articles analysing the correlation between the degree of bias of a country within a Han historical text and their distance, power and social structure in relation to the Han dynasty. In this work, the article seeks to explore the biases and stereotypes within official Han historical books, to argue that they changed their view and bias towards different countries along the Silk Road, depending on their distance from Han, their power compared to the Han, and whether they were nomadic or sedentary societies. Specifically speaking, the article will focus on three types of countries, from east to west along the Silk Road: the bordering, strong nomadic Xiong-Nu, the small sedentary or nomadic countries in the Western Regions far from Han, and the inaccessible sedentary Rome.

The present article will use the following three official Han history books, in order of earliest of the latest: Shi Ji, Book of Han and the Book of Later Han. Firstly, Shi Ji records the Han envoy named Zhang Qian's mission to the West, to find Ta-yue-chi and ally with it to fight the Xiong-Nu. Zhang Qian reported information about a lot of the western countries, including not only those he had been to but also those that he had only heard of. Secondly, the Book of Han preserves a lot of information from Si Ma Qian's Shi Ji, and because the Han Shu was written more than 100 years after when Shi Ji was written, the Han Shu included more information about the Xiong-Nu and the Western Regions. Lastly, the Book of Later Han, in 
comparison to the Han Shu, provides descriptions about countries farther away and never mentioned in the two previous books, such as Rome.

These primary sources show that the Han gradually learned more about these countries along the Silk Road and viewed these countries differently with bias. The present article will locate these views with biases, compare them and make an attempt to analyze the reason behind them using hindsight and through the perspectives of history and other relevant subjects like geography and politics.

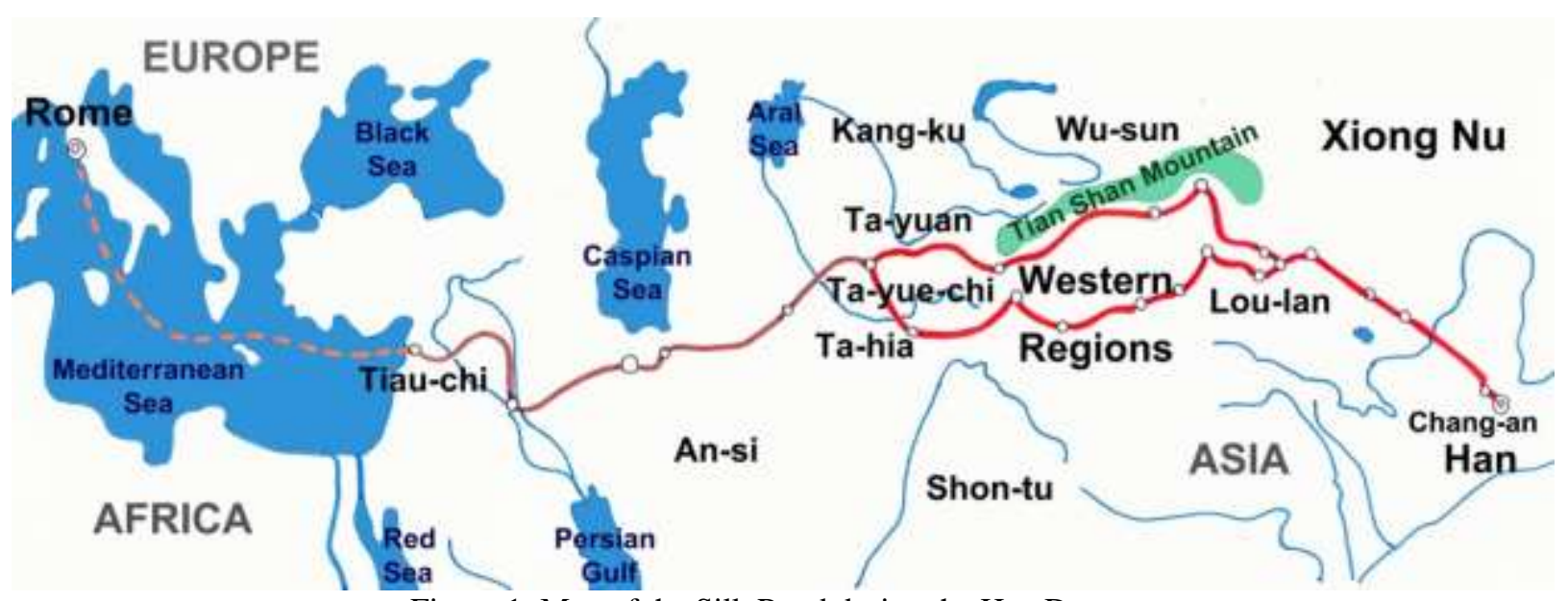

Figure 1: Map of the Silk Road during the Han Dynasty

Figure 1 shows the map of the Silk Road and the countries mentioned within Han historical texts. The red route marks the route of Han envoy Zhang Qian, who had embarked on the First mission to the Western Regions. The brown route marks the route of the Han envoy Gan Ying, who had embarked on the furthest mission to the west. He had originally planned to go to Rome, but only got to Tiau-chi in the end.

\section{THE DIMINISHMENT OF THE XIONG- NU}

Conflicts between nomadic and sedentary societies were key issues in ancient times. As an example, the First Emperor of Qin built the Great Wall in defense of the aggressive nomadic countries on the north, but most importantly for the Xiong-Nu. During the Han Dynasty, especially at the beginning, Xiong-Nu was a strong country, which caused many unavoidable border conflicts. The Silk Road was thus created by Zhang Qian as mentioned before.

Naturally, towards the biggest enemy Xiong-Nu, Han's attitude was hostile. Moreover, the Han army lost many soldiers after years of fighting. As the government had to tax the people heavily, many of those were starving. Even the Han emperor Wuti wrote an article blaming himself for the immense losses of the war, as it was his decision to fight the Xiong-Nu.[1, 2] Thus, to reduce the people's resentment and gain support from the public, the Han highlighted the impacts of the invasion of the Xiong-Nu and displayed the Xiong-Nu to be the one to blame while the Han was fighting for justice. Depicting the enemy as the devil country was a common method to gain public support, which is still used in modern times.
Thus, the Xiong-Nu, being a nomadic country that had many significant cultural differences with the sedentary and supercilious Han, was targeted by the Han for their barbarism. The Book of Han shows this through the passage that describes a debate between a previous Han eunuch who later surrendered to the Xiong- $\mathrm{Nu}$, and an envoy from the Han court.[3]

Firstly, the Han envoy criticized the Xiong-Nu for giving good food to the young rather than the elderly, as in Han, elders needed to be respected. The eunuch replied that Xiong-Nu regarded winning the war as their primary aim. Because the elderly could not fight, the Xiong-Nu supported the young and strong men with good food to increase the safety of their own country.

Then, the Han envoy continued to criticize another tradition of the Xiong-Nu: When the father dies, the son marries the stepmother and when a brother dies, the other brother marries the widow. This seemed extremely barbaric and immoral in the Han's eye. But Eunuch replied that the Xiong-Nu adopted this strategy as a way to maintain their families. The Xiong lived in severe environments and had high death rates due to the constant fighting. Thus, the Xiong-Nu needed to maintain the population by increasing the levels of procreation through forming new families after old ones had been lost.

From hindsight, the argument of the eunuch is very convincing. Xiong-Nu's traditions were very reasonable and effective for a constantly fighting nomadic country. Their culture and traditions were shaped by the environment the people are in, and should not be classified as right or wrong. It is only the Han court's bias, from the standpoint of their own culture, that makes the Xiong-Nu seem uncultured. 
To summarize, the Han and Xiong-Nu are equally powerful countries that border each other. They both competed for the resources, which led to large amounts of conflicts. However, because Xiong-Nu was the Hans enemies, and was also a nomadic country, these two factors made the Xiong-Nu the target for diminishment by the Han.

\subsection{The unimportance of the Western Regions}

In comparison to the Xiong-Nu, the Western Regions were further away from the Han and much weaker than the Han as well. As a result, the Han did not view these countries as important as the Xiong-Nu. Moreover, the Xiong-Nu had been defeated by the Han during Emperor Wuti's reign, which led to the Han becoming the country to control the Western Regions in replacement of the Xiong-Nu. Being protectorates to the Han, many countries in the Western Regions came to tribute to the Han, and even gave their princes to the Han as hostages, to show their respect and truthfulness. [4]

The Han Shu stated: "The Western Regions are far from the Han Taking over them would be barely beneficial, leaving them alone is not a loss as well'[5]. Hence, while the many countries in Western Regions have a treaty as a collective, the Xiong-Nu has its dedicated treaty in the Han Shu.

For most of these small countries in the west, the Book of Han only introduces their distance from Han, their population, their military size, and what countries are nearby. This shows that the Han cared most about the distance and power of these countries, which are two key factors that practically decide whether military conflict could happen or not. In addition, the Book of Han also mentions their living style, sedentary or nomadic (divided by the Tian Shan mountains), commodities, and traditions, which indicates that the Han was also interested in what the Han would get from these countries if it were to conquer or trade with them. However, these countries were too far away for both soldiers and traders to arrive, meaning they were, to an extent, irrelevant to the Han.

However, there were some exceptions to this rule. Several of these smaller countries in the Western Regions were more relevant and important to the Han for different reasons. Firstly, Lou-lan was one of the countries because it was the closest country to both the Han and the Xiong-Nu, and was in the key position of the Silk Road. Even though Lou-lan was quite a small country, the Han and Xiong both fought for it. As a result, Lou-lan was forced to sway between its two big neighbors, but in the end, the Han conquered the country. Secondly, the more powerful nomadic country Wu-sun became an important ally to the Han, by marrying the Han princess twice. Lastly, Ta-yuan (Ferghana) had excellent horses called the "blood sweating horse" which were not only loved by the Han emperor but were also crucial to strengthening the Han military. These important countries were thus recorded with more detail in the Book of Han.

The Han also had biases of these western countries. The nomadic Wu-sun people were described as "pigheaded, covetous as wolves, and utterly reliable"[6].The sedentary Ta-hia was described as "weak and afraid to fight" [7]. These descriptions show Han's pride in its own culture, as it views lowly of other countries.

To summarize, these western countries were generally further away and weaker than the Xiong-Nu. The longdistance also made it harder for the Han to trade with them and the weakness of their armies made them less of a threat to the Han. As a result, they were not as relevant as the Xiong-Nu and were mentioned much less in the Han histories. When mentioned, they were often diminished or described to be weak or barbaric.

\subsection{The idealization of faraway Rome}

In the Book of Han, it was recorded that the furthest place the Han envoys had traveled to was An-si, also known as Parthia. However, in the Book of Later Han, the furthest place the Han envoys had got became Tiauchi, also known as the Seleucid empire in Mesopotamia. In Tiau-chi, the Han envoys were stopped by sea and failed to arrive at Rome, their original goal. However, there were still pieces of information the Han envoys got about Rome, possibly from the Tiau-chi people or merchants from Rome. These pieces of information were written in the Book of Later Han. For example, one passage describes the five palaces in the city of Rome: "in the rooms of the palace, the pillars and tableware are really made of crystal". There were so many "gold silver and precious jewels, luminous jade, bright moon pearls, fighting cocks, rhinoceroses, coral yellow amber, opaque glass whitish chalcedony, red cinnabar, green gemstones, drawn gold-threaded and multi-colored embroideries, woven gold-threaded net, delicate polychrome silks painted with gold and asbestos cloth" [8] In the Han's view Rome was a rich, mythical and luxurious place.

Moreover, "Daqing" (The bigger Qin empire) was the name given to Rome as "the people were tall and honest, similar to the Han". This showed how the Han admired Rome as a highly civilized country, just like Han itself.

The praises from the Han above were very different from the previous negative and diminishing descriptions on the Xiong-Nu and other Western Regions. Thus, this shows that the Han idealized faraway countries that are unfamiliar to them.

A possible reason for this idealization is due to the large distance between Rome and Han. The distance was so far that neither the merchants nor the military 
from Han could reach Rome. Even though both were powerful countries, the distance factor prevented conflicts. Another reason may be because they were both civilized, sedentary nations, and are similar countries in general. As mentioned before, the Han even referred to Rome as another self. One final possible reason is that humans tend to imagine far away, unknown places to be heavenly and utopia-like. Even though the Han was incapable of reaching Rome, the lack of information allowed for more space for imagination and idealism.

In summary, because there was no possibility of conflict, due to the distance, and that Rome was a rich and civilized country that was similar to the Han, the Han admired and idealized Rome. The last example of Rome also shows a strong contrast between Rome's portrayal and the Xiong-Nu and Western regions' portrayal, mentioned in the previous sections.

\section{CONCLUSION}

The Silk Road has allowed the Han to learn more about countries along the Silk Road. However, the views of the Han were subjective and biased, as Han's perspective was dependent on their relationship with the other region and their own culture. The passage argues for that this relationship here is determined by the distance between the countries, the difference in culture and the difference in power.

With the emergence of the Silk Road from the Han Dynasty, the distance between the Han and certain countries was reduced. On the one hand, this benefitted the Han as it allowed for trade and the exchange of culture and knowledge. On the other hand, this led to more border/land conflicts. The shorter the distance, the more balanced the power of the countries as both have to coexist with one another. If one was weaker, the other would take over. Thus, the closer the distance, the more possible it is for conflicts and an enemy relationship. If the distance is far, the Han is unable to acquire much information about the country, and must rely on myths and idealizations to form their view on the country.

Additionally, whether they were nomadic or sedentary would also impact the view of the Han towards these countries. The Han being a sedentary nation looks down upon the more "barbaric", "non-civilised" nomadic people, The Han have self-pride and believe that their way of ruling is the most efficient and more effective than others. Due to this, seeing other countries adopting other strategies will make the view of the Han on them much more diminished. Thus, biases are formed on the basis of what way countries are being ruled as part of their culture.

Furthermore, power plays a key role in forming stereotypes and biases of a certain country. In the eyes of the Han, weak countries are not to be allies. The Han do not see them as a threat, consequently diminishing or not even mentioning them through their writing. If they are powerful like the Xiong Nu or Rome, the Han spend more time investing in research about these countries and thus produce more writing on these countries. Within these writings, they might even dimmish them or praise them depending on their relationship with that country.

"By taking history as a mirror", people can be more aware of the biases of human beings and countries in the current turmoil world. This will allow us to reflect on our mistakes and view things with fewer biases and stereotypes. "History doesn't repeat itself but it does rhyme". Thus, we must learn from history and find its patterns, which will in turn help better out understanding of the world.

For this piece of work, the article is specifically focused on primary sources produced by Han historians writing on the Silk road. To further develop the argument, the article will need to use secondary sources produced by other historians as a point of reference. Furthermore, the article can incorporate sources and knowledge from other fields such as politics and global relations in order to make connections that go beyond the original historical context.

\section{REFERENCES}

[1] Fan Ye (432) Treaties on the Western Regions. In : The book of later Han (Hou Han Shu)

[2] University of Washington, Daniel C Waugh. (1999) Section 1: Beginning relationships with the Xiongnu. In: Selections from the Han Narrative Histories. pp. 2-7

[3] Si Ma Qian (104) Chapter 110 : Treaties on the Xiong Nu. In: Shi Ji

[4] University of Washington, Daniel C Waugh. (1999) Section 2: Relations with the Hsiung-nu in the Reign of Emperor Wu-ti [140-87 BCE]. In: Selections from the Han Narrative Histories. pp. 9

[5] Ban Gu. (105) Chapter on the Western regions In: The book of Han (Han Shu).

[6] University of Washington, Daniel C Waugh. (1999) Section 7: Notes on Western Regions. In: Selections from the Han Narrative Histories. pp. $30-43$

[7] University of Washington, Daniel C Waugh. (1999) Section 3: The mission to the west by Zhang Qian. In: Selections from the Han Narrative Histories. pp. 11-17

[8] University of Washington, John E Hill. (2003) The Western Regions according to the Hou Hanshu The Xiyu juan "Chapter on the Western Regions"from Hou Hanshu 88 Second Edition. https://depts.washington.edu/silkroad/texts/hhshu/h ou_han_shu.html 